\title{
A FULL RANGE OF RESTORATIVE MATERIALS
}

Plandent stock a huge range of dental restorative materials for you to choose from. Whether you are looking for one of the latest, technologically advanced composite materials on the market or the amalgam that you have been using for some time, look no further.

Plandent keep in stock a full range of the leading brands of restorative dental materials: glass ionomers, compomers, composites, temporary cements or any of the accessories that you use on a daily basis. Many of these restorative materials are regularly promoted at extra special prices.
Due to the group buying power of Plandent and efficient supply chain, Plandent offer price reductions against recommended dental prices, meaning a great deal for you.

That's not all. Whether you're looking for dental consumables, a new handpiece or capital equipment, Plandent offer you everything you could possibly need for your surgery. All equipment sales are fully backed by Plandent's comprehensive after sales customer care programme.

For further information call free on 0500500322 .

\section{EASY ENTRY TO DIGITAL DIAGNOSTICS}

When practices buy a Galileos Compact from Sident Dental Systems it offers them a convenient entry to the world of 3D cone beam digital diagnostics, with the ability to upgrade for expansion. It also offers unparalleled functionality in diagnosis, planning and treatment because it also includes a CEPH facility.

Galileos 3D cone beam digital X-ray systems offer practices the power of integrated diagnostics and treatment planning via a single imaging system. It enables them to reduce risks, plan surgical interventions, coordinate treatment planning with colleagues and explain treatment to patients with even greater clarity, certainty and ease.

With their Cone Beam technology, they can calculate a large volume 3D image set (over 200 exposures) in a single low-dose scan lasting $15 \mathrm{sec}-$ onds or fewer. This 3D image set is then processed and displayed using their

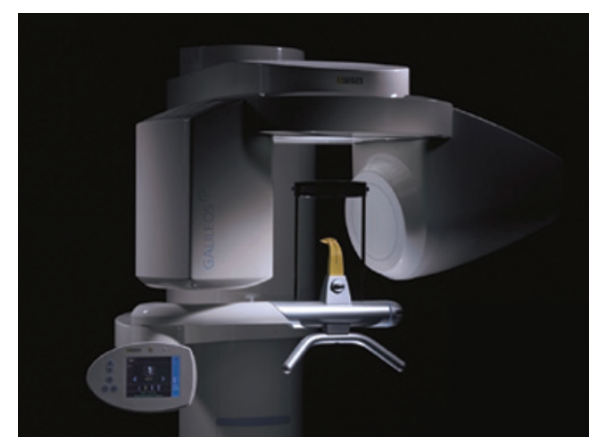

integrated GALAXIS 3D software.

The Galileos Compact presents its 3D images in perfect image quality and facilitates easy navigation and diagnosis in traditional PAN and TSA presentations. The Galileos Comfort offers CEPH views too. Both are all-in-one diagnosis and planning systems which offer a very short, low dose scanning cycle for optimum speed and efficiency.

For further information call 01932 582900 or visit www.sident.co.uk.

\section{GEL, AGENT AND COMPOSITE ALL IN ONE}

DMG's Constic self-etching and adhesive flowable composite eliminates both the etching and bonding steps, and saves valuable time too. Constic is faster, easier, more gentle and reliable. This 3-in-1 flowable composite combines etching gel, bonding agent and flowable composite in one single product. Possible sources of error are also minimised advantages not offered by conventional flowable composites requiring the use of a separate adhesive.

For further information contact your local dental dealer or DMG Dental Products (UK) Ltd on 01656789401 or visit www.dmg-dental.com. 